\title{
Modification of Chromosome Instability in Aspergillus nidulans
}

\author{
By K. W. BURR, J. A. ROPER* AND JANICE RELTON \\ Department of Genetics, The University, Sheffield S10 2TN, U.K.
}

(Received 1 March 1982; revised 5 June 1982)

\begin{abstract}
Strains of Aspergillus nidulans with a chromosome segment in duplicate show instability at mitosis; their colonies produce faster-growing sectors which arise from nuclei with spontaneous deletions in either duplicate segment. In an attempt to probe the deletion process, the effects of mutations causing sensitivity to UV treatment, and those of manganous ions, have been studied in strains carrying either $\mathrm{Dp}(\mathrm{I}, \mathrm{II})$ or $\mathrm{Dp}(\mathrm{III}, \mathrm{VIII})$. For comparison, the effects of $\mathrm{Mn}^{2+}$ on balanced and unbalanced diploids have also been examined. The $u v s E$ allele, which decreases intragenic mitotic crossing over in diploids, increased deletion frequency in strains with either duplication. The $u v s B$ allele, which increases intragenic mitotic crossing over in diploids, increased deletion frequency only in $\mathrm{Dp}(\mathrm{I}, \mathrm{II})$ strains; in addition, by causing early mitotic crossing over between the homologous segments, it produced some novel deletion products. $\mathrm{Mn}^{2+}$ substantially decreased the deletion frequency in $\mathrm{Dp}(\mathrm{I}, \mathrm{II})$ strains and decreased mitotic crossing over in diploids; it had no effect on Dp(III,VIII) strains. The results suggest that in haploid duplication strains there are two classes of spontaneous DNA lesions, recombinogenic and non-recombinogenic, both of which, failing repair, lead to deletion.
\end{abstract}

\section{INTRODUCTION}

Strains of Aspergillus nidulans with a chromosome segment in excess of the haploid genome (one segment in the normal position and one translocated to another chromosome) show instability at mitosis. Diverse genetic changes occur (Azevedo \& Roper, 1970), but the most frequently detected and thoroughly studied products of instability result from spontaneous deletions, variable in size and all apparently terminal, which occur in either duplicate segment (Bainbridge \& Roper, 1966; Nga \& Roper, 1968). All duplication strains so far tested undergo such deletions, though strains with different duplicate segments differ in the relative frequencies of breakpoints between and within their homologous segments (Birkett \& Roper, 1977).

Detection of deletion variants is usually easy; because of their reduced degree of imbalance they produce sectors which outgrow the duplication parent and it is possible, therefore, to investigate the effects on deletion frequency of genetic, chemical and other agents. So far, few agents have been tested and usually each has been studied with only one duplication strain (Cooke et al., 1970; Roper et al., 1972; Majerfeld \& Roper, 1978). Two of these studies (Roper et al., 1972; Majerfeld \& Roper, 1978), with caffeine and coumarin, respectively, suggested that deletions occur via a step which is repairable and that instability can be enhanced by chemical inhibition of DNA repair.

In further investigations of the deletion process, other agents which might affect its frequency and/or modalities have been sought. Newmeyer \& Galeazzi $(1974,1977,1978)$ showed the effect on Neurospora crassa duplication strains of a mutation which blocked meiosis and also caused sensitivity to UV. This suggested the possible value of studying the effects of mutations in $A$. nidulans (Jansen, 1970a, $b$; Fortuin, 1971 $a, b$ ) which, presumably through modifications of DNA repair, cause UV-sensitivity and alter the frequency of intragenic mitotic crossing over. Sermonti \& Morpurgo (1959) demonstrated the stabilizing effect of manganous chloride on

Abbreviations: CM, complete medium; MM, minimal medium; MSE, master strain E. 
colonies grown from mutagen-treated, diploid conidia of Penicillium chrysogenum. In that spontaneous and induced instability might respond to common modifying agents, the possible effects of $\mathrm{Mn}^{2+}$ on $A$. nidulans duplication strains merited investigation.

\section{METHODS}

Media. Minimal medium (MM) was Czapek-Dox medium with $1 \%(w / v)$ glucose. Complete medium (CM) contained yeast extract, hydrolysed casein, hydrolysed nucleic acids and vitamins. Solid media contained $2 \%$ (w/v) agar. Incubations were at $37^{\circ} \mathrm{C}$.

Methods of analysis. General methods of genetic analysis were those of Pontecorvo et al. (1953). Diploids were prepared by the technique of Roper (1952) and mitotic haploidization (Forbes, 1959) was facilitated by the use of $p$-fluorophenylalanine (Morpurgo, 1961). UV-sensitivity was determined by the qualitative test of Jansen (1970a).

Estimates of instability. Counts of sectors and of patches of mycelium showing the products of instability were made on colonies each grown from a single (uninucleate) conidium; this precluded the scoring of instability products which arose during culture propagation. Certain strains showed instability early in colony development and for these, where sectors were self-limiting in number, sector counts underestimated instability. In some such cases, individual conidia were grown for $3 \mathrm{~d}$ on $\mathrm{CM}$; conidia were sampled widely from each separate colony, plated on $\mathrm{CM}$, and the resulting colonies were scored for parental and non-parental conidial colour.

Strains. All strains were derived from Glasgow stocks. Master strain E (MSE), with markers on all eight linkage groups, was that of McCully \& Forbes (1965). The principal mutant alleles used (with linkage group, and arm where known), and the phenotypes determined, are listed below using the designations of Clutterbuck (1974): $w A 3$ (IIL), $y A 2$ (IR), white and yellow conidia, respectively; adE20(IR), biAI (IR), nicB8 (VIIR) and nic A2 (V), pabaA6 and pabaA108 (IR), proAl (IL), pyroA4 (IVR), riboAl (IL), riboB2 (VIIIR) and riboD5 (V), sB3 (VI) and $s C 12$ (IIIR), requirement for adenine, biotin, nicotinic acid, $p$-aminobenzoic acid, proline, pyridoxin, riboflavine and thiosulphate, respectively; galAl (IIIL) and fac $A 303$ (V), inability to grow on galactose and acetate, respectively; sUAladE20 (IL), suppressor of adE20; acrB2 (IIR), resistance to acriflavine. Strains with mutant alleles determining UV-sensitivity [utsB110 (IVR) and uvsE182(V)] were kindly supplied by Dr G. J. Jansen and Dr J. J. H. Fortuin whose allele designations have been retained.

Duplication strains and symbols. The basic constitutions of the duplication strains used are shown in Fig. 1. $\mathrm{Dp}$ (III,VIII) strains were obtained as recombinants from crosses involving a chromosomally-standard strain and one with T(III,VIII) (Bainbridge \& Roper, 1966). The original Dp(I,II) strain was isolated as a spontaneous duplication by Pritchard (1956) and recombinants were obtained from appropriate crosses of this original (cf. Nga \& Roper, 1968). For simplicity, allele numbers are omitted from the figures and main text. The haploid components of diploid strains are separated by the symbol $/ /$.

\section{RESULTS}

\section{Effects of uvs alleles}

Strains with Dp(I,II) or Dp(III,VIII) and $u v s B$ or $u v s E$ were obtained by appropriate crosses. For the former duplication, crosses with a $D p(I, I I)$ parent were needed as a reliable translocation stock [T(I,II)] was not available; for the latter duplication, each cross involved a translocation-free parent and one with T(III,VIII). Two checks of the recombinants were essential. It was necessary to establish, by genetic analysis and study of instability, the arrangement of mutant alleles in the duplicate segments; only those with arrangements shown in Fig. 1 were used. Although spontaneous genetic modifiers of instability are rare, they can be induced by UV treatment (Azevedo, 1975) and a check was needed against their possible introduction by recombination. Between four and six meiotic segregants for each combination of duplication and uvs allele were tested. In all cases many recombinants were inspected visually. No significant differences in behaviour were found among strains of each combination; in the chosen recombinants the various degrees and types of instability could be attributed to the different duplicate segments and uvs alleles.

\section{The uvsE allele}

Several criteria showed that $u v s E$ enhanced the instability of both $\mathrm{Dp}(\mathrm{I}, \mathrm{II})$ and $\mathrm{Dp}$ (III,VIII) strains. The results in Table 1 show the frequencies and phenotypes of sectors from whole-plate colonies but, in view of the early breakdown of the strains, the sector counts underestimated instability. For $\mathrm{Dp}(\mathrm{I}, \mathrm{II})$ uvsE it was possible to use the alternative, comparative estimation of instability (Table 2). 


\begin{tabular}{|c|c|c|c|c|c|c|}
\hline \multirow[b]{2}{*}{$\operatorname{Dp}(\mathrm{I}, \mathrm{II})$} & proA & IR & pabaA & $y A$ & + & + \\
\hline & & & & + & $a d E$ & biA \\
\hline
\end{tabular}

\begin{tabular}{|c|c|c|}
\hline & IIIL & + \\
\hline Dp(III,VIII) & VIIIR & ${ }_{s C} C$ \\
\hline
\end{tabular}

Fig. 1. The basic constitution of $\mathrm{Dp}(\mathrm{I}, \mathrm{II})$ and $\mathrm{Dp}(\mathrm{III}, \mathrm{VIII})$ strains used in this work. Loci are not spaced to scale and the meiotic recombination frequencies are approximate. The different chromosomes involved in each duplication are distinguished by broken and unbroken lines; centromeres are shown as circles. Dp(I,II) and Dp(III,VIII) carry terminal segments of IR and IIIL attached terminally and uninverted to IIR and VIIIR, respectively. (From Nga \& Roper, 1968 and Birkett \& Roper, 1977).

\section{Table 1. Effects of uvsE and uvsB on duplication strain instability}

Arrangements of alleles in the duplicate segments are shown in Fig. 1. Periods of incubation were adjusted to give a mean colony diameter of $7.6 \mathrm{~cm}$ for each genotype. Conidia for phenotypic tests were taken from the outside edges of sectors.

\begin{tabular}{|c|c|c|c|}
\hline Strain & $\begin{array}{l}\text { No. of } \\
\text { colonies } \\
\text { scored }\end{array}$ & $\begin{array}{r}\mathrm{To} \\
\text { of } \\
\text { (mean }\end{array}$ & $\begin{array}{l}\text { o. } \\
\text { ors } \\
\text { colony) }\end{array}$ \\
\hline Dp(III,VIII) $u v s^{+}$ & 212 & \multicolumn{2}{|c|}{$262(1 \cdot 24)$} \\
\hline Dp(III,VIII) uvsE & 108 & \multicolumn{2}{|c|}{$597(5 \cdot 53)$} \\
\hline \multirow[t]{2}{*}{$\mathrm{Dp}(\mathrm{III}, \mathrm{VIII})$ uvs $B$} & 185 & 194 & \\
\hline & & Yellow & Green \\
\hline $\mathrm{Dp}(\mathrm{I}, \mathrm{II}) u v s^{+}$ & 180 & $239(1 \cdot 33)$ & $93(0.52)$ \\
\hline $\mathrm{Dp}(\mathrm{I}, \mathrm{II}) u v s E$ & 108 & $291(2 \cdot 69)$ & $98(0.91)$ \\
\hline $\mathrm{Dp}(\mathrm{I}, \mathrm{II}) u v s B$ & 60 & $298(4 \cdot 97)$ & $93(1.55)$ \\
\hline
\end{tabular}

\begin{tabular}{|c|c|}
\hline \multicolumn{2}{|c|}{$\begin{array}{l}\text { Phenotypes of } \\
\text { tested sectors }\end{array}$} \\
\hline \multicolumn{2}{|c|}{$\begin{array}{l}65 \mathrm{~s}^{+}, 14 \mathrm{~s}^{-} \\
52 \mathrm{~s}^{+}, 44 \mathrm{~s}^{-} \\
32 \mathrm{~s}^{+}, 20 \mathrm{~s}^{-}\end{array}$} \\
\hline Yellow & Green \\
\hline $40 \mathrm{ad}^{+} \mathrm{bi}^{+}$only & $\begin{array}{l}48 \mathrm{ad}^{+} \mathrm{bi}^{+} \\
5 \mathrm{ad}^{-} \mathrm{bi}^{-}\end{array}$ \\
\hline $32 \mathrm{ad}^{+} \mathrm{bi}^{+}$only & $\begin{array}{r}2 \mathrm{ad}^{+} \mathrm{bi}^{+} \\
39 \mathrm{ad}^{-} \mathrm{bi}^{-}\end{array}$ \\
\hline $\begin{array}{r}107 \mathrm{ad}^{+} \mathrm{bi}^{+} \\
3 \mathrm{ad}^{+} \mathrm{bi}^{-}\end{array}$ & $\begin{array}{r}3 \mathrm{ad}^{+} \mathrm{bi}^{+} \\
50 \mathrm{ad}^{-} \mathrm{bi}^{-}\end{array}$ \\
\hline
\end{tabular}

The phenotypes of $u v s E$ sectors reinforced the view of enhanced instability. Approximately half of the Dp(III,VIII) uvsE sectors were thiosulphate-requiring which suggested total deletion, in equal frequency, of either duplicate sector; the control gave a significantly lower proportion of thiosulphate-requiring sectors and this was consistent with the results of Birkett \& Roper (1977) in which the majority of first-order sectors had terminal deletions whose proximal breakpoints were distal to the $s C$ locus. The green sectors of $\mathrm{Dp}(\mathrm{I}, \mathrm{II}) u v s E$, as compared with the green sectors of the control, were interpreted similarly.

Three yellow and two green sectors from $\mathrm{Dp}(\mathrm{I}, \mathrm{II}) u v s E$ were analysed meiotically and via the parasexual cycle and were shown to be of types A and B (Fig. 2), respectively. Although uvsE enhanced instability without modifying its end-product, there was evidence of probable differences in the $u v s E^{+}$and $u v s E$ routes to a balanced, stable, haploid state. Dp(I,II) $u v s E^{+}$gave yellow sectors without identifiable intermediates; $\mathrm{Dp}(\mathrm{I}, \mathrm{II})$ uvsE produced small, heavilypigmented patches with dark yellow conidia from which stable, yellow sectors arose. Isolates from such deteriorated patches were very unstable and some required more than one sub-culture before they yielded stable yellows. An isolate from one deteriorated patch was outcrossed to a standard strain and unstable, yellow, $u v s E^{+}$recombinants were recovered. These recombinants showed several steps of instability (as judged by sector morphology and growth rate) before achieving stability. The $u v s E$ allele had initiated a series of events which proceeded even in the later absence of this allele. The intermediates may have suffered sequential deletions on the route to becoming balanced haploids, but their very high instability precluded detailed genetic analysis. 


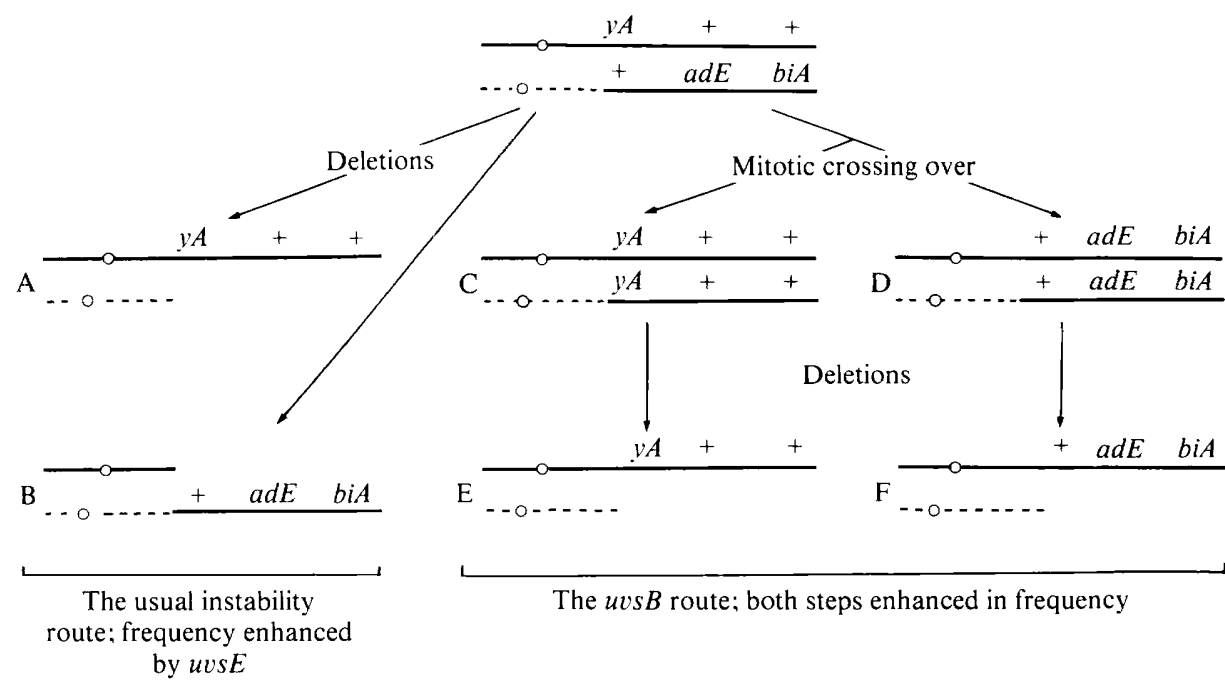

Fig. 2. Instability of $\mathrm{Dp}(\mathrm{I}, \mathrm{II})$ strains and the effects of $u v s E$ and $u v s B$. Only the main products of deletions are given $(A, B, E, F)$ without indication of their relative frequencies. Chromosomes I and II are represented by unbroken and broken lines, respectively; centromeres are shown as circles.

Table 2. Effects of uvsB and uvsE on $D p(I, I I)$

Conidial samples were from separate colonies, each of which was grown for $3 \mathrm{~d}$ from a single conidium. A total of 50 yellow variants from $\mathrm{Dp}(\mathrm{I}, \mathrm{II})$ uvs $B$ were cultured; 12 were stable and 38 sectored with a frequency similar to that of the duplication parent.

\begin{tabular}{|c|c|c|c|}
\hline \multirow[b]{2}{*}{ Strain } & \multirow{2}{*}{$\begin{array}{l}\text { Conidial } \\
\text { sample }\end{array}$} & \multicolumn{2}{|c|}{ No. of colonies } \\
\hline & & Green & Yellow* \\
\hline \multirow[t]{8}{*}{$\mathrm{Dp}(\mathrm{I}, \mathrm{II})$ uvs $E$} & 1 & 1002 & $52 \quad(4 \cdot 9)$ \\
\hline & 2 & 521 & $66(11 \cdot 2)$ \\
\hline & 3 & 383 & $94(19 \cdot 7)$ \\
\hline & 4 & 1883 & $62(3 \cdot 2)$ \\
\hline & 5 & 401 & $78(16 \cdot 3)$ \\
\hline & 6 & 2432 & $70 \quad(2 \cdot 8)$ \\
\hline & 7 & 2900 & $6 \quad(0 \cdot 2)$ \\
\hline & & 9522 & $428 \quad(4 \cdot 3)$ \\
\hline \multirow[t]{9}{*}{$\mathrm{Dp}(\mathrm{I}, \mathrm{II}) u s v B$} & 1 & 306 & $8 \quad(2.5)$ \\
\hline & 2 & 908 & $19 \quad(2 \cdot 0)$ \\
\hline & 3 & 686 & $15(2 \cdot 1)$ \\
\hline & 4 & 784 & $16 \quad(2 \cdot 0)$ \\
\hline & 5 & 162 & $3(1.8)$ \\
\hline & 6 & 976 & $22(2 \cdot 2)$ \\
\hline & 7 & 702 & $15 \quad(2 \cdot 1)$ \\
\hline & 8 & 780 & $20 \quad(2.5)$ \\
\hline & & 5304 & $118 \quad(2 \cdot 2)$ \\
\hline $\operatorname{Dp}(1, \mathrm{II}) u v s^{+}$ & $1-7$ & 12200 & 0 \\
\hline
\end{tabular}

* Numbers in parentheses are percentages of the total.

The uvs $B$ allele

This allele did not increase sector frequency in Dp(III,VIII) though the proportion of sectors which were thiosulphate-requiring was higher than in the control (Table 1). In the absence of a marked effect on sector frequency, no genetic analyses were made to explore this effect. 
Colonies of $\mathrm{Dp}(\mathrm{I}, \mathrm{II})$ uvs $B$ showed about a threefold increase in sectors as compared with their control (Table 1), but platings from small colonies (Table 2) showed that this underestimated the instability caused by $u v s B$. As compared with platings from small colonies of $\mathrm{Dp}(\mathrm{I}, \mathrm{II}) u v s E$, there was relatively little inter-sample variation in the frequencies of non-parental types. Yellow and green sectors from the edges of large colonies were stable and most of them had $\mathrm{ad}^{+} \mathrm{bi}^{+}$and $\mathrm{ad}^{-} \mathrm{bi}^{-}$phenotypes, respectively; this suggested total loss of one or other duplicate segment. The origin of the three yellow $\mathrm{ad}^{+} \mathrm{bi}^{-}$sectors, a type never observed from $u v s^{+}$controls, became clear on later analysis.

Three yellow $\mathrm{ad}^{+} \mathrm{bi}^{+}$and three green $\mathrm{ad}^{-} \mathrm{bi}^{-}$sectors were analysed meiotically and via the parasexual cycle and were shown to be of types $\mathrm{E}$ and F, respectively (Fig. 2). The unexpected constitution of the green sectors was explained as follows. Heavily-pigmented spots bearing dark green or dark yellow conidia were seen at the origin of a number of stable green or yellow sectors. Isolates from these had approximately the same high instability as the initial duplication strain, but the unstable greens $\left(\mathrm{ad}^{-} \mathrm{bi}^{-}\right)$and yellows $\left(\mathrm{ad}^{+} \mathrm{bi}^{+}\right)$gave only green, $\mathrm{ad}^{-} \mathrm{bi}^{-}$and yellow, $\mathrm{ad}^{+} \mathrm{bi}^{+}$sectors, respectively. It was likely that these were homozygous for the markers on one or other duplicate segment and, despite their instability, this was confirmed by meiotic and mitotic analyses. The unstable yellows and greens had arisen by mitotic crossing over between the point of attachment of the translocated segment and the $y A$ locus (types C and D, Fig. 2). Stable, balanced haploids then arose by preferential deletion (as in the $u v s^{+}$control) of the translocated segment. This explained the unstable yellow variants found in conidial platings from young colonies (Table 2); they arose by mitotic crossing over, not deletion.

The 110 yellow sectors tested from $\mathrm{Dp}(\mathrm{I}, \mathrm{II})$ uvs $B$ showed the distribution of mitotic crossovers

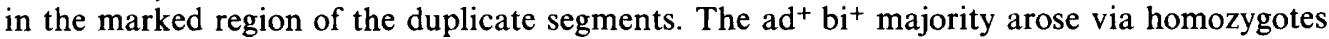
which resulted from crossing over in the interval between the attachment point of the translocated segment and the $y A$ locus. The three which were $\mathrm{ad}^{+} \mathrm{bi}^{-}$seemed likely to have involved crossing over in the $y A$ to $b i A$ interval. One sector, pro $A$ paba $A$ y $A$ biA; uvs $B ;$ nic $A$, was combined in diploid with MSE. On haploidization the diploid yielded (for chromosome I and II markers) the following: white, $14 \mathrm{pro}^{+} \mathrm{paba}^{+} \mathrm{ad}^{+} \mathrm{bi}^{+}, 4 \mathrm{pro}^{-} \mathrm{paba}^{-} \mathrm{ad}^{+} \mathrm{bi}^{-}$; yellow, 16 pro $^{+}$paba $^{+} \mathrm{ad}^{+} \mathrm{bi}^{+}, 3$ pro $^{-}$paba $^{-} \mathrm{ad}^{+} \mathrm{bi}^{-}$. The meiotic cross to MSE gave, in 117 progeny, no duplication types. These results showed that the yellow sector was chromosomally-standard and had $y \mathrm{~A}$ ad $E^{+}$biA on chromosome I. Mitotic crossing over in Dp(I,II) uvsB was polarized; 107 exchanges $(97.3 \%)$ occurred in the 9 meiotic units between the attachment point and the $y A$ locus and only $3(2.7 \%)$ in the 6 meiotic units between $y A$ and biA.

The role of the duplication in the instability was indicated by comparing the above results with those given by a chromosomally-standard, balanced diploid which was heterozygous $y A / / y A^{+}$and homozygous $u v s B / / u v s B$. Conidia from 3-d-old colonies of this diploid were plated and no yellow colonies were found in a total of 2100 scored. A total of 100 diploid colonies, each from a single conidium, were haploidized on $p$-fluorophenylalanine and all gave both yellow and green haploid segregants. In this balanced diploid there was no evidence of either frequent mitotic crossing over between the centromere and the $y \boldsymbol{A}$ locus, or deletions in chromosome $\mathrm{I}$.

\section{Effects of $\mathrm{Mn}^{2+}$ on mitotic instability}

After initial tests at various concentrations, $0 \cdot 01 \mathrm{M}-\mathrm{MnCl}_{2}$ was used throughout; at this concentration it had no detectable effect on colony morphology and its slight effects on linear growth rate were compensated by adjustments of the periods of incubation. $\mathrm{Mn}^{2+}$ produced a significant decrease in the various forms of mitotic instability of all tested strains except haploids with $\mathrm{Dp}$ (III,VIII) (Table 3). This was shown by the decrease of sector production and also, where they could be detected, by the decrease in patches of mycelium with non-parental conidial colour; the latter provided useful confirmation as they were less subject, especially in unbalanced strains, to the undefined competitive forces involved in the 'escape' of a sector from its parent.

A major proportion of the sectors produced by the balanced diploid, biA//MSE, are due to mitotic crossing over (Pontecorvo \& Käfer, 1958; Käfer et al., 1982) and this is so at least for the yellow sectors given by the unbalanced diploid Dp(I,II)//MSE (Case \& Roper, 1981). A common 
Table 3. Effects of $\mathrm{Mn}^{2+}$ on mitotic instability

The incubation periods were adjusted to give a mean colony diameter of $7.6 \mathrm{~cm}$ for each genotype. $\mathrm{MnCl}_{2}$ was used at a concentration of $0.01 \mathrm{M}$. Arrangements of alleles in the duplicate segments of duplication strains are shown in Fig. 1.

\begin{tabular}{|c|c|c|c|c|c|c|}
\hline Strain & Medium & $\begin{array}{c}\text { No. of } \\
\text { colonies } \\
\text { scored }\end{array}$ & \multicolumn{2}{|c|}{$\begin{array}{c}\begin{array}{c}\text { Total no. } \\
\text { of sectors } \\
\text { (mean per colony) }\end{array}\end{array}$} & \multicolumn{2}{|c|}{ (mean per colony) } \\
\hline \multirow{3}{*}{$\begin{array}{l}\text { Dp(III,VIII) } \\
\text { Dp(III,VIII) }\end{array}$} & \multirow{3}{*}{$\begin{array}{c}\mathrm{CM} \\
\mathrm{CM}+\mathrm{MnCl}_{2}\end{array}$} & \multirow{3}{*}{$\begin{array}{l}103 \\
102\end{array}$} & \multirow{2}{*}{\multicolumn{2}{|c|}{$\begin{array}{l}149(1.45) \\
168(1.65)\end{array}$}} & \multirow{3}{*}{\multicolumn{2}{|c|}{ Yellow }} \\
\hline & & & & & & \\
\hline & & & Yellow & Green & & \\
\hline $\mathrm{Dp}(\mathrm{I}, \mathrm{II})$ & $\mathrm{CM}$ & 172 & $198(1 \cdot 15)$ & $96(0 \cdot 56)$ & \multicolumn{2}{|c|}{$192(1 \cdot 12)$} \\
\hline $\mathrm{Dp}(\mathrm{I}, \mathrm{II})$ & $\mathrm{CM}+\mathrm{MnCl}_{2}$ & 181 & $21(0 \cdot 12)$ & $18(0 \cdot 10)$ & 24 & $\cdot 13)$ \\
\hline $\mathrm{Dp}(\mathrm{I}, \mathrm{II}) u v s B$ & CM & 40 & $228(5 \cdot 7)$ & $72(1 \cdot 8)$ & \multirow{2}{*}{\multicolumn{2}{|c|}{ Not scored }} \\
\hline \multirow[t]{2}{*}{$\mathrm{Dp}(\mathrm{I}, \mathrm{II}) u v s B$} & \multirow[t]{2}{*}{$\mathrm{CM}+\mathrm{MnCl}_{2}$} & \multirow[t]{2}{*}{41} & $93(2 \cdot 27)$ & $21(0 \cdot 51)$ & & \\
\hline & & & Yellow & White & Yellow & White \\
\hline biA//MSE & $\mathrm{CM}$ & 170 & $131(0 \cdot 77)$ & $60(0 \cdot 35)$ & $282(1.65)$ & $123(0 \cdot 72)$ \\
\hline$b i A / / \mathrm{MSE}$ & $\mathrm{CM}+\mathrm{MnCl}_{2}$ & 163 & $36(0 \cdot 22)$ & $15(0.09)$ & $86(0.52)$ & $34(0 \cdot 21)$ \\
\hline $\mathrm{Dp}(\mathrm{I}, \mathrm{II}) / / \mathrm{MSE}$ & $\mathrm{CM}$ & 44 & $176(4 \cdot 0)$ & $44(1 \cdot 0)$ & $158(3.59)$ & $38(0.86)$ \\
\hline $\mathrm{Dp}(\mathrm{I}, \mathrm{II}) / / \mathrm{MSE}$ & $\mathrm{CM}+\mathrm{MnCl}_{2}$ & 39 & $33(0 \cdot 85)$ & $4(0 \cdot 1)$ & $89(2 \cdot 28)$ & $13(0 \cdot 33)$ \\
\hline
\end{tabular}

basis could be proposed for the stabilizing effects of $\mathrm{Mn}^{2+}$ on diploids and on $\mathrm{Dp}(\mathrm{I}, \mathrm{II})$ strains, including those carrying $u v s B$. Majerfeld \& Roper (1978) suggested that coumarin increased the instability of $\mathrm{Dp}(\mathrm{I}, \mathrm{II})$ strains through its effect on recombinogenic lesions. Conversely, $\mathbf{M n}^{2+}$ appeared either to prevent these lesions or to abort their consequences. Dp(III,VIII) strains were not affected significantly by $\mathrm{Mn}^{2+}$ and, on the above hypothesis, it could be suggested that deletions in these strains do not arise via recombinogenic lesions. This is supported by the fact that coumarin does not enhance the instability of Dp(III,VIII) (J. A. Roper \& J. Relton, unpublished results).

\section{DISCUSSION}

Spontaneous deletions in Dp(I,II) strains occur mainly in the translocated segment, at or near its point of attachment (Nga \& Roper, 1968); those in Dp(III,VIII) strains occur with equal frequency in either segment, with a distribution roughly proportional to the meiotic recombination frequencies between markers in the analysed intervals (Birkett \& Roper, 1977). In $\mathrm{Dp}(\mathrm{I}, \mathrm{II})$ and $\mathrm{Dp}(\mathrm{III}, \mathrm{VIII})$ the proximal ends of the untranslocated duplicate segments are respectively some 15 and 80 meiotic units from their centromeres, and, although this might be relevant, it gives no immediate explanation for their differences in instability patterns. As far as can be judged from genetic analysis, both duplications involve terminal attachments of duplicate segments and there is now substantial evidence of the frequent, spontaneous occurrence of these in A. nidulans (C. E. Sexton \& J. A. Roper, unpublished). Furthermore, deletions appear to be terminal and only in rare instances do they produce what may be abnormal telomeres (Birkett \& Roper, 1977). The existence of terminal attachments and deletions in Drosophila melanogaster has been doubted (Muller \& Herskowitz, 1954; Roberts, 1975) but seem now to be established firmly (Novitski et al., 1981; Bicudo, 1981). Novitski et al. (1981) interpreted terminal attachments as being consistent with a divisible telomere and compatible also with the hypotheses of its palindromic structure and replication (Holmquist \& Dancis, 1976; Cavalier-Smith, 1974; Bateman, 1975), though substantiation of this must await more knowledge of telomere sequences and properties (Rubin, 1977; Forte \& Fangman, 1979). Discussion of terminal deletions, and factors which affect them, can be considered only in the framework of this incomplete information.

Newmeyer \& Galeazzi (1977) and Birkett \& Roper (1977) advanced similar models to explain terminal deletions in $N$. crassa and $A$. nidulans, respectively. To account for the precise and 
preferential deletion of a translocated segment, the former authors proposed excision of an intrachromosomal loop formed by pairing of the telomere and a residual homologous segment at the attachment point. The latter authors proposed a more general model of intrachromosomal loops formed by pairing of the telomere with internal sequences of partial homology; this would account for deletions in a chromosome with no attached segment, and, through occasional mispairing, would explain the production of what appeared to be abnormal telomeres which generated instability.

Whatever the processes of deletion in duplication strains of $A$. nidulans features common to, or different in, $\mathrm{Dp}(\mathrm{I}, \mathrm{II})$ and $\mathrm{Dp}(\mathrm{III}, \mathrm{VIII})$ could be identified by the effects of $u v s$ alleles and $\mathrm{Mn}^{2+}$. The $u v s E$ allele, which was known to decrease the frequency of intragenic mitotic crossing over, increased instability of both $\mathrm{Dp}(\mathrm{I}, \mathrm{II})$ and $\mathrm{Dp}(\mathrm{III}, \mathrm{VIII})$ showing that the $u v s E^{+}$function restrains instability in both duplication strains. The $u v s B$ allele, known to increase intragenic mitotic crossing over, was effective only with $\mathrm{Dp}(\mathrm{I}, \mathrm{II})$; it increased the deletion frequency and also the frequency of mitotic crossing over between the homologous chromosome I segments. Both consequences could have resulted from the persistence, or increased frequency, of recombinogenic lesions at or near the attachment point. It was interesting that in $\mathrm{Dp}(\mathrm{I}, \mathrm{II})$ uvs $B$ the frequency of mitotic crossing over fell sharply distal to the attachment point which, in this respect, showed centromere-like properties (Pontecorvo \& Käfer, 1958; Minet et al., 1980).

The action of $\mathrm{Mn}^{2+}$ in reducing mitotic crossing over in balanced and unbalanced diploids suggested either a reduced frequency, or stabilization, of recombinogenic lesions. This is consistent with its stabilizing action on Dp(I,II) and its lack of significant effect on $\mathrm{Dp}(\mathrm{III}, \mathrm{VIII})$. Diverse genetic effects of $\mathrm{Mn}^{2+}$ have been reported. These include the induction of chromosomal gene mutations in prokaryotes (Demerec \& Hanson, 1951; Orgel \& Orgel, 1965) and mitochondrial mutations in yeast (Putrament et al., 1973, 1975). $\mathrm{Mn}^{2+}$ has also been shown to reduce the fidelity of DNA replication in some in vitro systems (Hall \& Lehman, 1968; for other references see Loeb et al., 1978 and Hibner \& Alberts, 1980). Apart from the observations by Sermonti \& Morpurgo (1959), which prompted the present work, only three reports are known which might be relevant to a stabilizing action of $\mathrm{Mn}^{2+}$. Whiting et al. (1979) showed that $\mathrm{Mn}^{2+}$ stimulated unscheduled DNA synthesis in human cell cultures treated with hydrazines; Litman (1971) reported that both the rate and fidelity of replication of $\mathrm{G} \cdot \mathrm{C}$-rich DNA by a Micrococcus luteus polymerase were enhanced by $\mathrm{Mn}^{2+}$ as compared with $\mathrm{Mg}^{2+}$; finally, Eichhorn et al. (1971) showed that $\mathrm{Mn}^{2+}$ stabilized the DNA helix by preventing unwinding and/or facilitating reannealing. The findings of Litman (1971) apply only to G C Crich sequences and there is no reason to suppose that these are involved in mitotic crossing over. In addition, Forte $\&$ Fangman (1979) indicated that the termini in yeast chromosomes are A $\cdot \mathrm{T}$ rich, and it is the termini which may be involved in the deletion process in Aspergillus duplication strains. Our tentative view is that helix stabilization (Eichhorn et al., 1971) can best explain the reduction by $\mathrm{Mn}^{2+}$ of both mitotic crossing in diploids and deletions in $\mathrm{Dp}(\mathrm{I}, \mathrm{II})$ strains. The ineffectiveness of $\mathrm{Mn}^{2+}$ in $\mathrm{Dp}$ (III,VIII) strains would then have to be ascribed to lesions in which there is no effective stabilization.

The principal aim of this work was to explore the nature and fate of DNA lesions in $A$. nidulans duplication strains. As in earlier studies, the results have revealed the overall complexity, and probable diversity, of events leading to deletions. Some clarification of the possible roles of genome imbalance and organization in instability may emerge from further studies with the many different duplication strains now available. Cases of chromosomal instability are difficult to analyse genetically, but on several scores they merit attention. They are important for understanding the fidelity of mitosis, they can have application in the test of potential mutagens (Roper, 1971; Käfer et al., 1982) and they provide models for clinically important chromosomal changes in man.

\section{REFERENCES}

Azevedo, J. L. (1975). Altered instability due to genetic changes in a duplication strain of Aspergillus nidulans. Genetical Research 26, 55-61.
Azevedo, J. L. \& Roper, J. A. (1970). Mitotic nonconformity in Aspergillus: successive and transposable genetic changes. Genetical Research 16, 79-93. 
BAinbridge, B. W. \& Roper, J. A. (1966). Observations on the effects of a chromosome duplication in Aspergillus nidulans. Journal of General Microbiology 42, 417-424.

BATEMAN, A. J. (1975). Simplification of palindromic telomere theory. Nature, London 253, 379-380.

BicuDo, H. E. M. DE C. (1981). Deletion and addition of chromatin on the tips of polytene chromosomes of Drosophila arizonensis. Brazilian Journal of Genetics 4, 471-475.

BirketT, J. A. \& Roper, J. A. (1977). Chromosome aberrations in Aspergillus nidulans. In The Genetics and Physiology of Aspergillus, pp. 293-303. Edited by J. E. Smith \& J. A. Pateman. New York: Academic Press.

CASE, B. L. \& Roper, J. A. (1981). Mitotic processes which restore genome balance in Aspergillus nidulans. Journal of General Microbiology 124, 9-16.

Cavalier-Smith, T. (1974). Palindromic base sequences and replication of eukaryotic chromosome ends. Nature, London 250, 467-470.

Clutterbuck, A. J. (1974). Aspergillus nidulans. In Handbook of Genetics 1, pp. 447-510. Edited by R. C. King. New York: Plenum Press.

CoOke, P., Roper, J. A. \& Watmough, W. (1970). Trypan blue induced deletions in duplication strains of Aspergillus nidulans. Nature, London 226, 276-277.

Demerec, M. \& Hanson, J. (1951). Mutagenic action of manganous chloride. Cold Spring Harbor Symposia on Quantitative Biology 16, 215-218.

EICHHORN, C. L., BERGER, N. A., Butzow, J. J., Clark, P., Rifkind, J. M., Shin, Y. A. \& Tarien, E. (1971). The effects of metal ions on the structure of nucleic acids. Advances in Chemistry, series 100 (Bioinorganic Chemistry) 7, 135-154.

FORBES, E. (1959). Use of mitotic segregation for assigning genes to linkage groups in Aspergillus nidulans. Heredity 13, 67-80.

ForTe, M. A. \& Fangman, W. L. (1979). Yeast chromosomal DNA molecules have strands which are cross linked at their termini. Chromosoma $\mathbf{7 2}$, $131-150$.

Fortuin, J. J. H. (1971a). Another two genes controlling mitotic intragenic recombination and recovery from UV damage in Aspergillus nidulans. I. UV sensitivity, complementation and location of six mutants. Mutation Research 11, 149-162.

FortuIN, J. J. H. $(1971 b)$. Another two genes controlling mitotic intragenic recombination and recovery from UV damage in Aspergillus nidulans. II. Recombination behavior and X-ray sensitivity of $u v s B$ and $u v s E$ mutants. Mutation Research 11, 265277.

Hall, Z. W. \& Lehman, I. R. (1968). An in vitro transversion by a mutationally altered T4-induced DNA polymerase. Journal of Molecular Biology 36, 321-333.

HibNER, U. \& ALberTS, B. M. (1980). Fidelity of DNA replication catalysed in vitro on a natural DNA template by the $\mathrm{T} 4$ bacteriophage multi-enzyme complex. Nature, London 285, 300-305.

Holmquist, G. P. \& Dancis, P. B. (1976). Telomere replication, kinetochore organizers, and satellite DNA evolution. Proceedings of the National Academy of Sciences of the United States of America 76, 45664570 .
JANSEN, G. J. O. (1970a). Survival of uvsB and $u v s C$ mutants of Aspergillus nidulans after UV irradiation. Mutation Research 10, 21-32.

JANSEN, G. J. O. (1970b). Abnormal frequencies of spontaneous mitotic recombination in $u v s B$ and $u v s C$ mutants of Aspergillus nidulans. Mutation Research 10, 33-41.

KÄFER, E., SCOTt, B. R., DORN, G. L. \& StafFord, R. (1982). Aspergillus nidulans: systems and results of tests for chemical induction of mitotic segregation and mutation. Mutation Research 98, 1-48.

Litman, R. M. (1971). The differential effect of magnesium and manganese ions on the synthesis of poly $(\mathrm{dG} \cdot \mathrm{dC})$ and Micrococcus luteus DNA by Micrococcus luteus DNA polymerase. Journal of Molecular Biology 61, 1-23.

Loeb, L. A., Weymouth, L. A., Kunkel, T. A., Gopinathan, K. P., Beckman, R. A. \& Dube, D. K. (1978). On the fidelity of DNA replication. Cold Spring Harbor Symposia on Quantitative Biology 43, 921-927.

MAJERFELD, I. H. \& Roper, J. A. (1978). The effects of coumarin on the frequency of deletions in a duplication strain of Aspergillus nidulans. Molecular and General Genetics 159, 203-206.

McCully, K. S. \& Forbes, E. (1965). The use of $p$ fluorophenylalanine with 'master strains' for assigning genes to linkage groups. Genetical Research 6, 352-359.

Minet, M., Grossenbacher-Grunder, A. \& ThurIAUX, P. (1980). The origin of a centromere effect on mitotic crossing over. Current Genetics 2, 53-60.

MORPURGO, G. (1961). Somatic segregation induced by $p$-fluorophenylalanine. Aspergillus Newsletter 2, 10.

Muller H. J. \& Herskowitz, I. H. (1954). Concerning the healing of chromosome ends produced by breakage in Drosophila melanogaster. American Naturalist $\mathbf{8 8}, 177-208$.

Newmeyer, D. \& Galeazzi, D. R. (1974). A genetic factor which causes deletion of duplications in Neurospora. Genetics 77, 48.

Newmeyer, D. \& Galeazzi, D. R. (1977). The instability of Neurospora duplication $D p(I L \rightarrow I R)$ H4250, and its genetic control. Genetics 85, 461-487.

NewMEYER, D. \& GaleazZI, D. R. (1978). A meiotic UV-sensitive mutant that causes deletion of duplications in Neurospora. Genetics 89, 245-269.

NGA, B. H. \& RoPER, J. A. (1968). Quantitative intrachromosomal changes arising at mitosis in Aspergillus nidulans. Genetics 58, 193-209.

Novitski, E., Grace, D., Strommen, C. \& Puro, J. (1981). Terminal chromosome attachments. American Journal of Human Genetics 33, 55-60.

OrGel, L. \& ORGEL, L. E. (1965). Induction of mutations in bacteriophage T4 with divalent manganese. Journal of Molecular Biology 14, 453-457.

PONTECORVO, G. \& KäFER, E. (1958). Genetic analysis by means of mitotic recombination. Advances in Genetics 9, 71-104.

Pontecorvo, G., Roper, J. A., Hemmons, L. M., Macdonald, K. D. \& Bufton, A. W. J. (1953). The genetics of Aspergillus nidulans. Advances in Genetics 5, 141-238.

PRITChaRd, R. H. (1956). A genetic investigation of some adenine-requiring mutants of Aspergillus nidulans. Ph.D. thesis, Glasgow University, U.K. 
Putrament, A., Baranowska, H. \& Prazmo, W. (1973). Induction by manganese of mitochondrial antibiotic resistance mutants in yeast. Molecular and General Genetics 126, 357-366.

Putrament, A., Baranowska, H., Ejchart, A. \& Prazmo, W. (1975). Manganese mutagenesis in yeast. IV. The effects of magnesium, protein synthesis inhibitors and hydroxyurea on $\mathrm{Ant}^{\mathrm{R}}$ induction in mitochondrial DNA. Molecular and General Genetics 140, 339-347.

ROBERTS, P. A. (1975). In support of the telomere concept. Genetics 80, 135-142.

ROPER, J. A. (1952). Production of heterozygous diploids in filamentous fungi. Experientia 8, 14-15.

ROPER, J. A. (1971). Aspergillus. In Chemical Mutagens 2, pp. 343-363. Edited by A. Hollaender. New York \& London: Plenum Press.
Roper, J. A., Palmer, H. M. \& Watmough, W. A. (1972). Mitotic non-conformity in Aspergillus nidulans: the effects of caffeine. Molecular and General Genetics 118, 125-133.

RuBIN, G. M. (1977). Isolation of a telomeric DNA sequence from Drosophila melanogaster. Cold Spring Harbor Symposia on Quantitative Biology 42, 10411046.

Sermonti, G. \& Morpurgo, G. (1959). Action of manganous chloride on induced somatic segregation of Penicillium chrysogenum diploids. Genetics 44, 437447.

Whiting, R. F., Wei, L. \& Stich, H. F. (1979). Enhancement by transition metals of unscheduled DNA synthesis induced by isoniazid and related hydrazines in cultured normal and xeroderma pigmentosum human cells. Mutation Research 62, 505-515. 